\title{
Imaging finding in diabetic mastopathy: A case report
}

\author{
Lynda Nadine Gui Bile*1, Hanane Antoun ${ }^{1}$, Judicael Ahoury², Raissa Kabas ${ }^{2}$, Estelle Valerie Ohui-Acko², Frederique \\ Amrar-Vennier ${ }^{1}$ \\ ${ }^{1}$ Department of Imaging, Sud-Francilien Hospital center, Corbeil-Essonne, France \\ ${ }^{2}$ Medical School, Felix Houphouet Boigny University, Abidjan, Côte d'Ivoire
}

Received: October 1, 2018

DOI: $10.5430 /$ ijdi.v5n2p19
Accepted: November 4, $2018 \quad$ Online Published: November 11, 2018

URL: https://doi.org/10.5430/ijdi.v5n2p19

\begin{abstract}
Diabetic mastopathy is an uncommon immunologic breast disease occurring usually in patients under long-term insulin treatment. It can pose a question of differential diagnosis with breast cancer especially in case of family history of breast cancer. We report the radiological diagnostic approach of a case of diabetic mastopathy with family history of breast cancer. The mammogram was nonspecific. Ultrasound showed two suspicious masses of right breast without suspicious enhancement on MRI. Diabetic mastopathy was confirmed on histology without cancer cells. Diabetic mastopathy is a diagnostic challenge and needs to be suspected in all patients with type I diabetes. Image-guided biopsy confirmation remains mandatory. The literature is briefly reviewed.
\end{abstract}

Key Words: Diabetic mastopathy, Imaging, Mammography, MRI, Ultrasound

\section{INTRODUCTION}

Diabetic mastopathy is classified as a rare non-infectious breast disease of immunologic origin occurring late in the development of insulin-dependent diabetes in young patients. ${ }^{[1]}$ Cases and series of cases have been published in the literature. It is a benign pathology, however, in the context of family history of breast cancer, there may pose a question of differential diagnosis with malignant pathology. Mammogram is often not very specific. Ultrasonography may reveal single or multiple uni- or bilateral lesions requiring MRI for characterization of lesions. the purpose of this case was to evaluate the use of MRI for diagnostic orientation and the role of image-guided biopsy in histological confirmation of diabetic mastopathy with multiple suspicious lesions on ultrasound.

\section{Case presentation}

A 36 years old woman with type I diabetes under insulin since the age of 10 with two family history of breast cancer (maternal grandmother at age 40 and maternal aunt at age 60) was referred for the exploration of a painful swelling of the outer areolar of the left breast. It was first performed a mammography using a digital camera DR Hologic Selenia 3D; then an ultrasound Toshiba Aplio 400 device with probes 12 and 18. The patient had breast density c-type of the BI-RADS classification, ${ }^{[2]}$ no suspicious mass, architectural distortion, nor calcifications. There was a discrete asymmetry of density with a general denser homogeneous appearance of the left outer glandular area mainly visible on craniocaudal view and the presence of two left axillary ganglia of ordinary appearance (see Figure 1). On ultrasound, the glandular texture was globally heterogeneous. In the left breast, two

\footnotetext{
* Correspondence: Lynda Nadine Gui Bile; Email: lynda_gui@yahoo.fr; Address: Department of Imaging, Sud-Francilen Hospital center, CorbeilEssonne, France.
} 
outer sub areolar hypoechogenic masses were observed, one to $2 \mathrm{~cm}$ from the nipple of $20 \mathrm{~mm} \times 11 \mathrm{~mm}$ and the other over the radius of $2 \mathrm{~cm}$ to $4 \mathrm{~cm}$ from the nipple of $12.3 \mathrm{~mm}$ $\times 10 \mathrm{~mm}$. both being $1.5 \mathrm{~cm}$ apart (see Figure 2); They had an irregular shape, parallel orientation with respect to the cutaneous plane, indistinct non-circumscribed contours, with attenuation of the ultrasonic beam and without Doppler signal. The right breast did not have a cystic or tissue focused abnormality. The breast was classified as BIRADS 4. Given the family history and the BI-RADS classification, a malignant cause could not be ruled out, requiring a mammary MRI to characterize the ultrasound abnormalities before biopsy. The MRI examination was performed on a GE $1.5 \mathrm{~T}$ device. The protocol included Axial MR images: T1-weighted image, T2 -weighted image, Fat saturated T2-weighted image, Axial slice diffusion, Fat saturated T1-weighted and with im- age subtraction and CADstream dedicated processing. The breasts had a minimal background parenchymal enhancement with hyposignal bilateral diffusion of the lesions. On the T2 fat saturated view, two supra-external, bilateral, symmetrical masses were found in micro-punctuated hypersignal, with very little progressive enhancement, in favor of a benign process (see Figure 3). Ultrasound-guided biopsy was therefore performed (14 Gauge, Bard) showing a fibrous dystrophic mammary parenchyma with an appearance of lymphocytic lobulitis in both biopsied areas (see Figure 4) in favor of fibrous breast disease without atypical elements in according with diabetic mastopathy. There were no cancer cell. The patient was reclassified BIRADS 2 with ultrasound control at 4 months, which showed a doubling of the initial size of lesions. She was therefore referred to the endocrinologist for a specialized treatement.
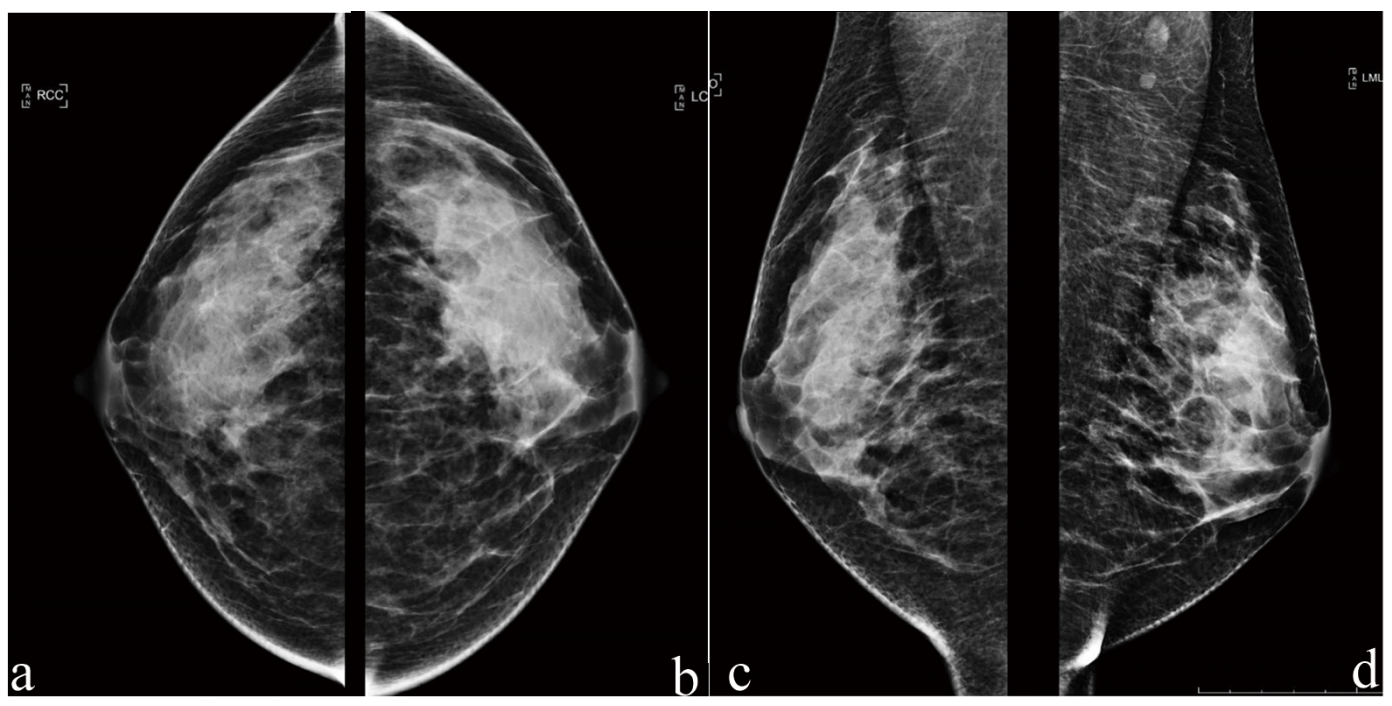

Figure 1. Mammography in craniocaudal view ( $a$ and b) and oblique incidence (c and d). Discrete asymmetry of density without detectable mass, architectural distortion or site of micro calcifications

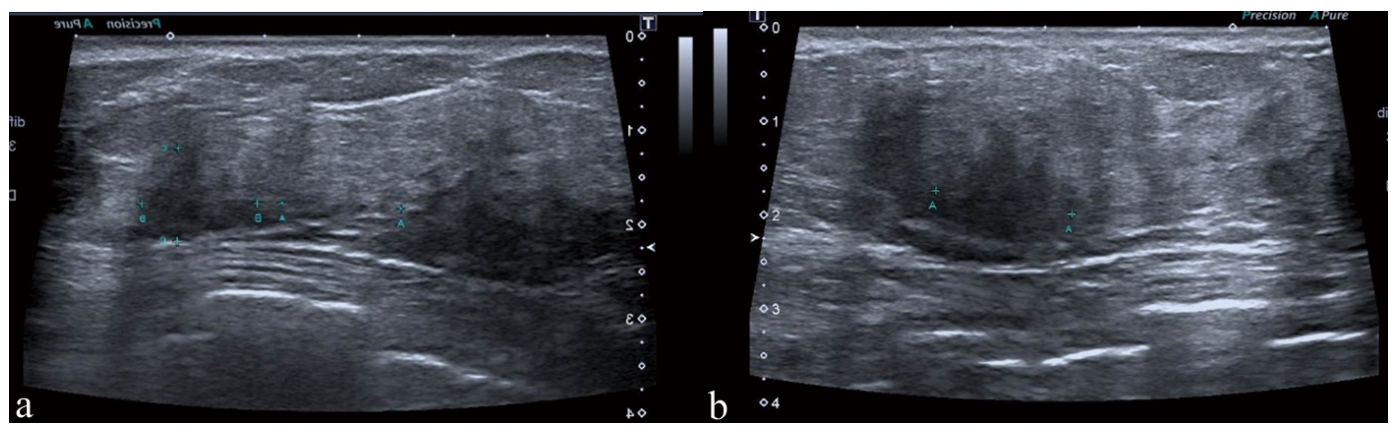

Figure 2. 2D cross sectional ultrasonography. a. Two irregular hypo echogenic masses above the left outer areolar with indistinct outline. b. The largest mass 

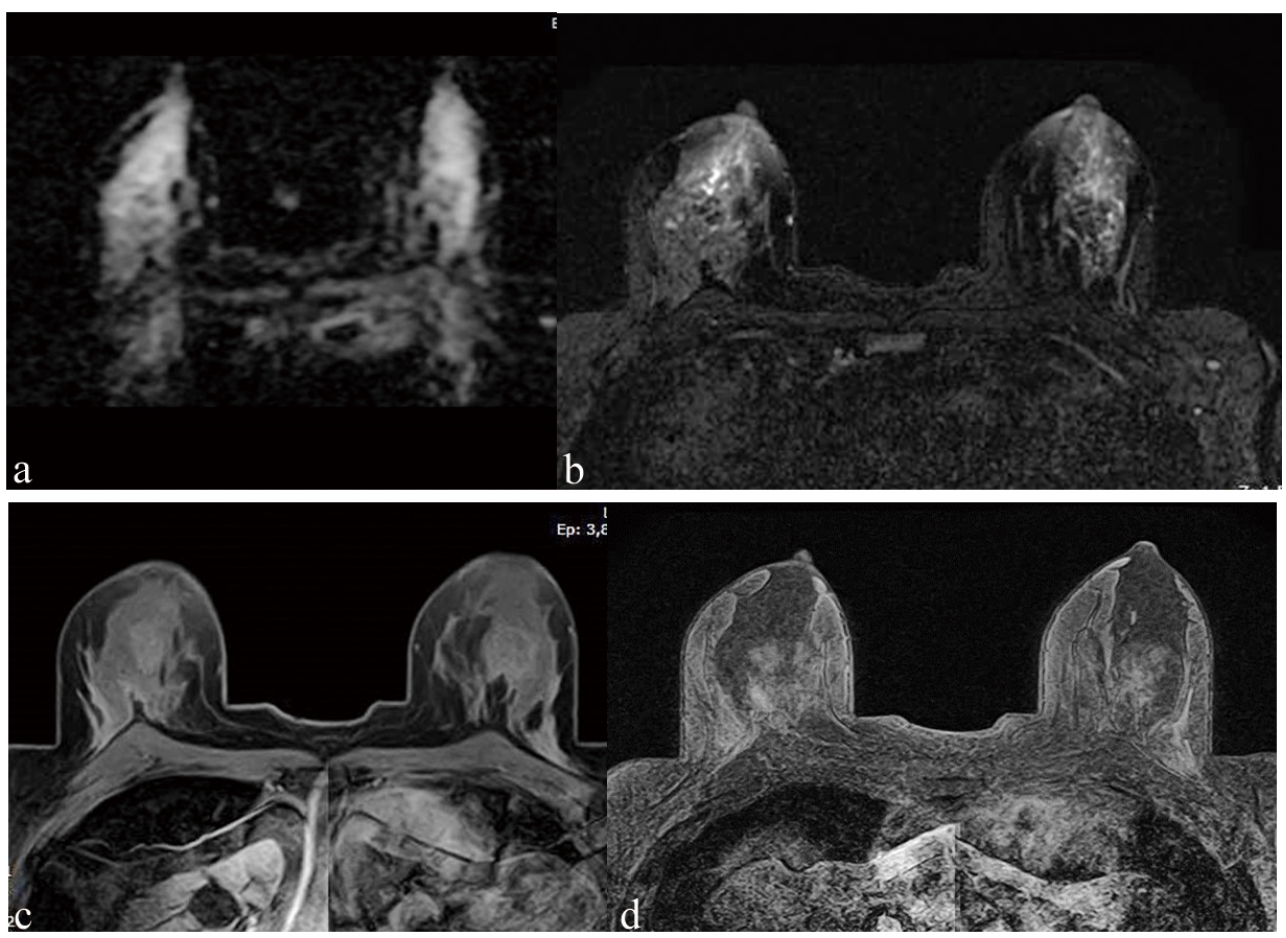

Figure 3. Breast MR Images. a. Axial diffusion cut: bilateral hyposignal lesions. b. T2 Fat Sat axial section showing a hyposignal of the two masses. $\mathrm{c}$ and d. Axial cuts gado early and late: discrete bilateral progressive enhancement of the masses
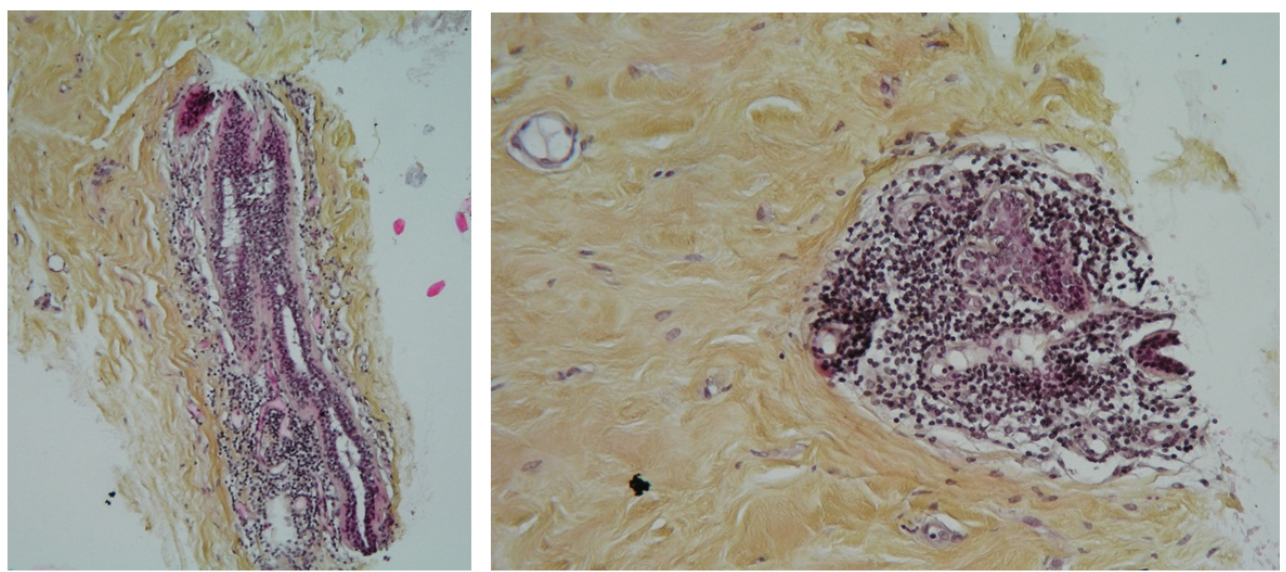

Figure 4. Histological sections showing an abundant and hyalinized fibrous stroma with epithelioid fibroblasts associated with perivascular tropism lymphocytosis

\section{Discussion}

Diabetic mastopathy, also known as lymphocytic mastopathy or sclerosing lymphocytic lobulitis, ${ }^{[3]}$ is an uncommon anatomic and clinical entity involved in benign immunologic breast disease. It is mostly found in young women, in the long-term evolution of insulin-dependent diabetes. Some cases in patients with type II diabetes have also been reported. ${ }^{[4-6]}$ Sporadic cases have also been described in men. ${ }^{[7]}$ In the radiological diagnostic procedure, mammogra- phy appears to be not very contributive as in our observation. $\mathrm{Kim}^{[4]}$ and Dorokhova ${ }^{[8]}$ respectively reported $78 \%$ and $69 \%$ of normal mammograms in their series. Only a focal or diffuse asymmetry of density is sometimes evidenced without visual mass. A retrieved case reporting suspected microcalcifications was associated with intra ductal carcinoma. ${ }^{[9]}$

Ultrasonography is more sensitive than mammography to detect in our case a heterogeneous mass classified BIRADS 4 , which presented according to the criteria of classification 
BI-RADS 2013, an irregular shape, an orientation parallel to the cutaneous plane with uncircumscribed contours and attenuation of the ultrasound beam. This description was notified in most of the clinical cases described in the literature ${ }^{[10,11]}$ and in the series of Moschetta et al. $(77 \%),{ }^{[12]}$ by Kim et al. (69\%). ${ }^{[5]}$ However, the mass may assume a benign trait (BIRADS 3) as in $66 \%$ of the Dorokhova series ${ }^{[8]}$ which can be subject to either surveillance or immediate histology depending on the case.

MRI, when performed in diagnostic doubt or to assess the extent of multiple lesions, generally confirms the benignity of lesions observed by the absence of hypersignal diffusion with normality of the apparent coefficient diffusion (ACD) and the absence of contrast enhancement. This can allow postponing possible micro biopsies in the absence of a family history of breast cancer. ${ }^{[13]}$ However, the mass may have a hypersignal diffusion which does not allow to immediately exclude a malignant process. ${ }^{[14]}$ After injection of contrast agent, we have demonstrated in our case a gradual enhancement in favor of benignity with a type I enhancement curve also reported by Sakuhara et al., ${ }^{[15]}$ tunckbilec ${ }^{[16]}$ and costantini. ${ }^{[13]}$ However, diabetic mastopathy may have all malignancy criteria at MRI, i.e., hypersignal diffusion with a decrease in ADC coefficient and massive and early enhancement with a type III enhancement curve. ${ }^{[10]}$ It has also been highlighted in literature, the coexistence of breast cancer with diabetic mastopathy. ${ }^{[9]}$ Therefore, it seems necessary to always take biopsies in a diabetic patient before a mass classified BIRADS 4 more or less associated with suspicious micro calcifications or having a family history of breast cancer. The management of this pathology involved for several case radical surgery lesions with a significant risk of recurrence. The radio-clinical monitoring of lesions with balanced diabetes is the recommended therapeutic attitude.

\section{Conclusion}

In the radiological approach of the diabetic mastopathy, mammogram appears little contributive compared to Ultrasonography and MRI. Ultrasonography and MRI usually allow making the diagnosis of benignity. However, biopsy specimens must necessarily be taken in case of diagnosis doubt or in the presence of a family history of breast cancer in the patient.

\section{Conflicts of InTEREST Disclosure}

The authors declare that they have no competing interests.

\section{REFERENCES}

[1] Salem C, Chopier J, Thomassin-Naggara I. Affections rares du sein EMC - Radiologie et Imagerie médicale : Génito-urinaire - Gynécoobstétricale - Mammaire. 2011: 1-13 [Article 34-800-A-20].

[2] D’orsi CJ, Sickles EA, Mendelson EB, et al. ACR BI-RADS Atlas, Breast Imaging Reporting and Data System. Reston, VA, American College of Radiology; 2013.

[3] Williams PH, Rubin CM, Theaker JM. Sclerosing lymphocytic lobulitis of the breast. Clinical Radiology. 1995; 50: 165-7. https: //doi.org/10.1016/S0009-9260(05)83048-X

[4] Cirrito D, Orlando AA, Narese F, et al. Diagnostic and therapeutic management of diabetic mastopathy: a case report. Clin Ter. 2015; 166: $169-72$.

[5] Accurso A, Della Corte GA, Rocco N, et al. Int J Surg. 2014; 12 Suppl 1: 79-82.

[6] Kim J, Kim EK, Kim MJ, et al. Diabetic mastopathy: imaging features and the role of image-guided biopsy in its diagnosis. Ultrasonography. 2015. https ://doi.org/10.14366/usg. 15052

[7] Akahori H, Kaneko M, Kiyohara K, et al. A rare case of diabetic mastopathy in a Japanese man with type 2 diabetes mellitus. Intern Med. 2009; 48: 915-9. PMid:19483361. https://doi.org/10.2 169/internalmedicine.48.1834

[8] Dorokhova O, Fineberg S, Koenigsberg T, et al. Diabetic mastopathy, a clinicopathological correlation of 34 cases. Pathol Int. 2012; 62: 660-4. PMid:23005592. https : //doi .org/10.1111/j.1440-1 $827.2012 .02853 . \mathrm{x}$
[9] Yamashita M, Ogawa T, Hanamura N, et al. An uncommon case of $\mathrm{T} 1 \mathrm{~b}$ breast cancer with diabetic mastopathy in type II diabetes mellitus. Breast Cancer. 2013; 20: 92-6. PMid:19789948. https : //doi.org/10.1007/s12282-009-0172-2

[10] Leconte I, Feger C, Berlière M, et al. Mastopathie diabétique. Imagerie de la femme. 2005; 15: 161-3. https://doi.org/10.101 6/S1776-9817(05) 80654-6

[11] Costantini M, Belli P, Magistrelli A, et al. MRI in insulin-dependent diabetic mastopathy. A case report. Rays. 2002; 27: 307-12. PMid:12696293.

[12] Moschetta M, Telegrafo M, Triggiani V, et al. Diabetic mastopathy: a diagnostic challenge in breast sonography. J Clin Ultrasound. 2015; 43: 113-7. PMid:25327165.

[13] Isomoto I, Wada T, Abe K, et al. Diagnostic utility of diffusionweighted magnetic resonance imaging in diabetic mastopathy. Clin Imaging. 2009; 33: 146-9. PMid:19237061. https://doi .org/10 .1016/j.clinimag. 2008.09.004

[14] Nasu H, Ikeda A, Ogura H, et al. Two cases of diabetic mastopathy: MR imaging and pathological correlation. Breast Cancer. 2015; 22 : 552-6. PMid:22976289. https ://doi .org/10.1007/s12282-0 12-0407-5

[15] Sakuhara Y, Shinozaki T, Hozumi Y, et al. MR imaging of diabetic mastopathy. Am J Roentgenol. 2002; 179: 1201-3. PMid:12388498. https://doi.org/10.2214/ajr.179.5.1791201

[16] Tuncbilek N, Karakas HM, Okten O. Diabetic fibrous mastopathy: dynamic contrast-enhanced magnetic resonance imaging findings. Breast J. 2004; 10: 359-62. PMid:15239797. https://doi.org/ $10.1111 / \mathrm{j} .1075-122 \mathrm{X} .2004 .21382 . \mathrm{x}$ 